\title{
Erratum to: Osteonecrosis of the jaw (ONJ) in renal cell cancer patients after treatment including zoledronic acid or denosumab
}

\author{
Vittorio Fusco • Alberto Bedogni • Giuseppina Campisi
}

Published online: 26 April 2014

(C) Springer-Verlag Berlin Heidelberg 2014

\section{Erratum to: Support Care Cancer}

DOI 10.1007/s00520-014-2159-6

The original version of this article unfortunately contained one mistake.

The reference number 11 is erroneously reported by Hansen et al.

The correct reference number 11 is :

Smidt-Hansen T, Folkmar TB, Fode K, Agerbaek M, Donskov F. Combination of zoledronic Acid and targeted therapy is active but may induce osteonecrosis of the jaw in patients with metastatic renal cell carcinoma. J Oral Maxillofac Surg 2013 Sep;71(9):1532-40. doi: 10.1016/j.joms. 2013.03.019. Epub 2013 May 1.

The online version of the original article can be found at http://dx.doi.org/ 10.1007/s00520-014-2159-6.

V. Fusco $(\bowtie)$

Oncology Unit, SS Antonio e Biagio e Cesare Arrigo Hospital, Via

Venezia 16, 15121 Alessandria, Italy

e-mail: vittoriofusco1@tin.it

A. Bedogni

Department of Surgery, Section of Oral and Maxillofacial Surgery,

University and Hospital Trust of Verona, P.le L.A. Scuro 10,

Verona 37134, Italy

G. Campisi

Department of Surgical, Oncological and Oral Sciences- Sector of

Oral Medicine, Palermo University, Via del Vepro 129,

Palermo 90127, Italy 